\title{
Determinación de las patologías bucales de la población infantil y adolescente en dos pueblos originarios del NEA argentino.
}

Determination of the mouth pathologies of the infantile and adolescent population in two original peoples of the Argentine NEA.

Fecha de Recepción

23 de septiembre de 2013
Determinação de doenças bucais de crianças e adolescentes em duas cidades da linha argentino de origem.
Becaria de Iniciación de la Secretaria

General de Ciencia y Técnica.

E-mail: valedelanghe.gmail.com

María M. González Doctora en Odontología. Titular cátedra Clínica Estomatológica. FOUNNE.
Aceptado para su publicación

22 de noviembre de 2013

\section{Resumen}

En la Argentina, los pueblos originarios históricamente han sido sometidos a un intenso proceso de exclusión, dando lugar a la escasa información disponible respecto de la problemática abordada, las patologías bucales que afectan a las comunidades Toba y Mocoví. Los objetivos propuestos fueron diagnosticar las patologías frecuentes de tejidos blandos y duros de la cavidad bucal en las comunidades Toba y Mocoví y comparar las patologías más frecuentes de ambas comunidades, según sexo y edad. Estudio descriptivo, de corte transversal. Se examinaron $10 \mathrm{I}$ individuos cuyas edades oscilaron entre 3 y 20 años, previa obtención del consentimiento informado, se realizaron exámenes clínicos estomatológicos. Resultados: gingivitis marginal crónica $0,69 \%$ en la comunidad Mocoví y $0,67 \%$ en la Toba. Caries dental $0,80 \%$ en la comunidad Mocoví y $0,97 \%$ en la Toba. El sexo femenino y el grupo etario de 6 a 13 años en ambas comunidades fueron los más afectados. Conclusiones: en ambas comunidades las alteraciones detectadas fueron gingivitis marginal crónica y caries dental que se relacionan con la escasa higiene y la dificultad de acceso a centros de salud para su atención, por razones geográficas.

Palabras claves

Lesiones Estomatológicas - Toba - Mocoví. 
REVISTA FACULTAD DE ODONTOLOGÍA

ISSN No 1668-7280 - Vol. VI № 2 - 2013

35
INVESTIGACIÓN

Determinación de las patologías bucales

de la población infantil y adolescente en

dos pueblos originarios del NEA argentino.

\section{Summary}

In Argentina, the indigenous people have historically been subjected to an intense process of exclusion, leading to the limited information available regarding the issues at stake, oral pathology affecting communities Mocoví and Toba. The proposed objectives were frequent pathologies diagnose soft and hard tissues of the oral cavity in Toba and Mocoví communities and compare the most common diseases of both communities, by sex and age. The study was descriptive, cross-sectional, examined $10 \mathrm{l}$ individuals whose ages ranged from 3 to 20 years, after informed consent, clinical examinations were performed. Results: $0.69 \%$ chronic marginal gingivitis in Mocoví community and $0.67 \%$ in the Toba. Dental Caries in the Mocoví community $0.80 \%$ and $0.97 \%$ in Toba. Female sex and age group of 6-13 years in both communities were the most affected. Conclusions: in both communities alterations detected were chronic marginal gingivitis and tooth decay, which are related to poor sanitation and lack of access to health centers for care for geographical reasons.

\section{Keywords}

Stomatological injury - Toba - Mocovi.

\section{Resumo}

$\mathrm{Na}$ Argentina, os povos indígenas têm, historicamente, sido submetida a um intenso processo de exclusão, levando a pouca informação disponível sobre as questões em jogo, patologia oral, afetando comunidades e Mocovi Toba. Os objetivos propostos foram patologias frequentes diagnosticar tecidos moles e duros da cavidade oral em comunidades Toba e Mocovi e comparar as doenças mais comuns de ambas as comunidades, por sexo e idade. A descritivo, transversal. Foram examinados $10 \mathrm{I}$ indivíduos com idades entre 3 e 20 anos, após a obtenção do consentimento informado, os exames clínicos foram realizados estomatologista. Resultados: $0.69 \%$ comunidade gengivite marginal crônica Mocovi e 0,67\% no Toba. Cárie Dentária na comunidade 0,80\% e $0,97 \%$ Mocovi em Toba. Sexo feminino e faixa etária de 6-13 anos as duas comunidades foram as mais afetadas. Conclusões: Em ambas as comu- nidades das alterações detectadas foram crônica marginal gengivite e cáries são associados com a falta de higiene e falta de acesso aos centros de saúde para os cuidados, por razões geográficas.

\section{Palavras chave \\ Lesões estomatológicas - Toba- Mocovi.}

\section{Introducción}

En la República Argentina, los pueblos originarios históricamente han sido sometidos a un intenso proceso de exclusión, marginación y exterminio, es por ello que la información sobre la temática de los mismos se encuentra dispersa y poco sistematizada. Esta situación ha dado lugar a la escasa información respecto de la problemática abordada, las patologías bucales que afectan las dos comunidades Toba y Mocovíl.

La información científica sobre registros, relevamientos epidemiológicos sobre el estado de salud bucal, referente a las patologías estomatológicas fue escasa o nula, especialmente en relación a la población infantil y adolescente motivo de este estudio.

Estudios realizados en un asentamiento de la etnia Tobas en Los Pumitas en Rosario, concluyeron que las enfermedades bucales diagnosticadas estaban relacionadas con la dificultad de acceso a tratamientos especializados como prótesis dentales, y con respecto a los niños, estos no asisten a la consulta odontológica por presentar dentición temporaria, y que a su entender, estas piezas dentarias no requieren algún tipo de procedimiento odontológico. Adjudican las enfermedades bucales presentes a dificultad de acceso a la atención odontológica².

No obstante, se encontraron estudios realizados en otros países, en Colombia en 22 comunidades indígenas, durante un período de 9 meses, se describieron que los individuos de cada núcleo familiar maneja la higiene oral según su propio criterio y según su grado de educación personal. La higiene bucal que realizaban los indígenas era inadecuada, existiendo un desconocimiento del uso del cepillo dental, habiendo en promedio un cepillo dental por familia ${ }^{3}$.

En la población infantil de la comunidad indígena Sikuani de Colombia, se detectaron altos índices de caries y placa bacteriana producto de 
REVISTA FACULTAD DE ODONTOLOGÍA

ISSN No 1668-7280 - Vol. VI № 2 - 2013

36
INVESTIGACIÓN

De Langhe - González una falta de motivación. Atribuyeron estos resultados el hecho de pertenecer a sectores menos favorecidos en cuanto al acceso a la atención odontológica debido a la distancia que deben recorrer estas etnias 4 .

En la Universidad de Adelaide en el sur de Autralia, se efectuaron estudios en aborígenes niños y adultos, describiendo la experiencia de caries particularmente alta en los niños, casi dos veces más que en los niños no aborígenes. Asimismo la enfermedad periodontal es más frecuente en adultos, con un $63 \%$ de cálculo en jóvenes de 18 a 24 años 5 .

En Ontario, Canadá, se llevó a cabo un estudio comparativo en niños aborígenes y no aborígenes con respecto al estado de salud bucal y específicamente referido a la caries dental, concluyendo que existen diferencias significativas entre los niños aborígenes y no aborígenes, siendo decreciente esta tendencia en los niños aborígenes ${ }^{6}$.

En el sur de Australia en un estudio de la población infantil de aborígenes y caucásicos en edad escolar con respecto al estado de salud bucal, los resultados fueron: el doble de casos de gingivitis y enfermedad periodontal en los niños aborígenes, se observaron anomalías oclusales como maloclusión severa, apiñamiento dentario anterior en un $5,5 \%$ en aborígenes y $3,7 \%$ en caucásicos. En cuanto a la caries los niños aborígenes presentaron mayor número de dientes cariados que los niños caucásicos, relacionando los resultados con la atención odontológica no disponible ${ }^{7}$.

Un estudio longitudinal llevado a cabo en 145 indígenas australianos nacidos en Darwin entre 1987 y 1990 cuyas edades oscilaron entre 6 y 8 años y II y I 3 años y de 18 a 20 años, demostraron que las diferencias más marcadas en la severidad de caries dental de dientes CPO fue entre los 18 y 20 años $^{8}$.

En el oeste de Australia, donde se ubican comunidades indígenas que viven en zonas rurales, se realizó un estudio comparativo retrospectivo de datos clínicos obtenidos en dos servicios asistenciales, que prestaban atención odontológica, uno a niños aborígenes y otro a no aborígenes, el cual ratificó que la práctica dominante fue extracción dental en los aborígenes, lo que indicaría la escasa prevención y cuidados del estado de salud bucodental por parte de esta comunidad aborigen?.
En la comunidad indígena de Torres Strait Islander, Queensland, Australia un estudio relacionó la incapacidad de acceso a los servicios asistenciales por razones geográficas o económicas con la salud oral de los niños indígenas, en comparación con los no indígenas de Australia, concluyendo que los niños indígenas son más propensos a tener caries dental en todas las edades afectando la dentición temporaria y permanente; y como resultado arrojaron que la edad de 6 años, el 72\% de los niños indígenas tenían alguna caries dental en comparación con el $38 \%$ de niños no indígenas ${ }^{10}$.

Con el propósito de comparar las características sociodemográficas de salud oral de los niños indígenas y no indígenas que asisten a la atención en la Clínica de Pika Wiya Servicio de Salud Dental y en Port Augusta Escuela de Servicio Dental (SDS) en la región central - norte de Australia del Sur, se demostró que la población más propensa y socialmente desfavorecida fueron los niños en edad pre escolar, del sexo femenino e indígenas, siendo la prevalencia de caries dental severa en ambas denticiones, acentuándose en Port Augusta esta problemática. Concluyéndose que las desigualdades de salud en los niños indígenas encontradas, proponiendo un enfoque más profundo y programas de mejoramiento del estado de salud bucodental en estas comunidades".

También en el norte de Australia, se analizó la relación entre la gravedad de la presencia de la caries dental y el bienestar emocional y social en una población indígena adulta joven, tomando como determinantes sociales de la salud el empleo, ingresos, vivienda, racismo y el nivel de conocimiento cultural. Los resultados obtenidos relacionan la salud bucal más con los hombres quienes son dueños del cepillo dental y al acceso de los tratamientos dentales en cambio las mujeres están asociadas al dolor, consumo de alcohol y a la discriminación racial y de género, tal lo indica la cultura indígena en que viven ${ }^{12}$.

En América del sur, en un estudio sobre la salud oral en 508 guaraníes en el Estado de Río de Janeiro, Brasil, realizado entre diciembre de 2006 y abril de 2007, los resultados concluyeron que la caries dental fue la más frecuente, representando el $92,3 \%$ del índice CEOD a los 5 años, el $100 \%$ del CPOD a los 12 años y $46,4 \%$ entre 
los 15 y 19 años. Además detectaron la presencia de cálculo dental en un $20,9 \%$ y sangrado gingival en un $11,36 \%{ }^{13}$.

En cuanto a la información disponible en la Argentina, especialistas y representantes indígenas determinaron en el año 2008, que la ausencia de información específica que describa la realidad epidemiológica de las patologías en estas comunidades constituye la principal dificultad para la mejora de la situación de salud de las mismas ${ }^{14}$.

Según el Foro de Investigación en Salud "La población indígena en Argentina presenta un perfil epidemiológico complejo atravesado por una mayor mortalidad y vulnerabilidad que en el resto de la población, desnutrición infantil, Chagas, Tuberculosis y otras enfermedades infectocontagiosas evitables." La organización mundial de la salud (OMS) en el año 1993 determinó la importancia del estudio de la variable étnica para la obtención de datos en las investigaciones de salud en los países de Latinoamérica y con la intervención de las Naciones Unidas en 1994 se expresó la importancia de la salud de las comunidades aborígenes ${ }^{15}$.

Teniendo en cuenta la escasa información disponible en relación al estado de salud bucal y fundamentalmente de las patologías estomatológicas que tienen asiento en los tejidos blandos y de la caries dental y enfermedad periodontal que impactan sobre el estado de salud para toda la vida, se consideró de interés realizar este trabajo para generar conocimientos científicos epidemiológicos, tomando a la población infanto juvenil de las comunidades indígenas Toba y Mocovíi ${ }^{16}$.

Los Objetivos propuestos fueron:

Diagnosticar las patologías frecuentes de tejidos blandos y duros de la cavidad bucal en las comunidades Toba y Mocoví. Comparar las patologías más frecuentes de ambas comunidades, según sexo y edad.

\section{Materiales y Métodos}

El estudio fue descriptivo, de corte transversal, realizado en $10 \mathrm{I}$ individuos cuyas edades oscilaron entre 3 y 20 años, en el período comprendido de mayo de 2010 a noviembre de 2011 , en dos pueblos originarios: 55 individuos de la comunidad Toba residente en el Lote 60 departamento de General San Martín, Provincia del Chaco y 46 individuos de la comunidad Mocoví con asiento en el Paraje El Paraisal, Los Laureles, Reconquista, provincia de Santa Fe.

\section{Criterios de inclusión}

Se incluyeron en la muestra a individuos de ambos sexos, cuyas edades oscilaron entre de 3 y 20 años, con denticiones temporarias, mixtas y permanentes para la observación de patologías bucodentales, colaboradores activos.

\section{Criterios de exclusión}

Se excluyeron a los individuos poco colaboradores y que no se encuentren con las edades contempladas en el estudio.

Los materiales utilizados fueron los siguientes: kit de inspección según las normas de bioseguridad, material descartable (guantes, baberos, vasos), tríadas de inspección, lupa, linterna, material impreso (historias clínicas unificadas de la Facultad de Odontología, UNNE, Consentimientos Informados y Planillas de Registro confeccionadas para tal fin donde fueron volcados los datos obtenidos de los exámenes clínicos estomatológicos), cámara fotográfica, cepillos dentales, cremas dentales y obsequios realizados por alumnos de la cátedra Clínica Estomatológica.

\section{Selección de pacientes}

Previa explicación del proyecto de investigación y compromiso de participar por parte de los individuos, se obtuvo el consentimiento informado (aprobado por Resolución No 767/09 y I86/I I CD) por parte de los padres y/o tutores y el asentimiento en caso de los niños.

\section{Metodología}

Se realizaron los contactos con las autoridades pertinentes para solicitar los permisos y firmas de los acuerdos de trabajo en cada pueblo indígena correspondiente. Asimismo, se realizaron entrevistas con los jefes comunales de cada comunidad indígena para obtener el acceso y realizar el trabajo de campo ${ }^{17}$.

Los individuos fueron distribuidos en 3 grupos etarios: de 3 a 6 años, de 7 a 12 años y de 13 a 
20 años, teniendo en cuenta las denticiones temporarias, mixtas y permanentes respectivamente. Se confeccionaron las historias clínicas correspondientes. Se realizaron exámenes clínicos estomatológicos aplicando la semiotecnia correspondiente y considerando las siguientes características: ubicación, forma, color, tamaño, número, aspecto superficial, textura, consistencia, profundidad, movilidad, adhesión a planos profundos, repercusión a distancia y sintomatología en cada patología observada.18 Examen clínico fue dividido en:

I. Examen de tejidos blandos en base al siguiente orden: los labios en reposo (cerrados) y abiertos, teniendo en cuenta sus zonas, partes constitutivas. Mucosa yugal anterior o retrocomisural, media y posterior. Paladar duro y blando. Lengua: cara dorsal, ventral y bordes laterales anterior, medio y posterior. Piso de la boca e Istmo de las fauces. Encías libre y adherida o insertada. 19 Todos los datos obtenidos fueron registrados en planillas confeccionadas para tal fin.

2. Examen de tejidos duros: se evaluó el estado de salud buco-dental de cada individuo, se examinó el estado de la dentición registrándose la presencia de patologías dentarias en odontogramas de la historia clínica unificada de la Facultad de Odontología, UNNE.

3. Se realizaron tomas fotográficas de las patologías observadas.

4. Posteriormente los datos obtenidos fueron ordenados, evaluados y analizados mediante estudio estadístico SPSS versión II.0.

\section{Implicancias éticas}

Se trabajó teniendo en base a los derechos colectivos de los pueblos originarios, teniendo en cuenta las disposiciones legales a nivel nacional y provincial. Asimismo tratándose de poblaciones vulnerables y siguiendo los criterios macro éticos y la necesidad de justificación para investigar en ellos se realizó una jornada de extensión denominada "Educación y prevención de la salud bucal" destinada a niños y sus familias, donde se desarrollaron las siguientes actividades: a. Enseñanza de técnicas de cepillado, b. Capacitación sobre medidas preventivas sobre los cuidados de salud bucal, c. Entrega de obsequios a los participantes.

\section{Resultados}

El estudio fue realizado en $10 \mathrm{I}$ individuos, 46 (46\%) de la comunidad Mocoví, 37 (80\%) femeninos y 9 (20\%) masculinos, y $55(54 \%)$ de la comunidad Toba, 38 (69\%) femeninos y 17 (31\%) masculinos.

Las patologías de tejidos blandos más frecuentes en la comunidad Mocoví fueron: gingivitis marginal crónica en 9 casos (0,69\%), (fig. I) siguiéndole el pólipo pulpar con 2 casos $(0,15 \%)$, macroglosia y periodontitis con I caso $(0,08 \%)$. En la comunidad Toba fueron: gingivitis marginal crónica en 6 casos $(0,67 \%)$, seguido de pólipo pulpar con I caso (0, I I\%), herpes simple (fig. 2 ) con I caso $(0$, I I \%) y queilitis descamativa crónica (fig. 3) con I caso (0, I I\%) Tabla I.

Las patologías de tejidos duros diagnosticadas en los Mocovíes fueron: caries dental (fig. 4) en 35 casos $(0,80 \%)$, seguido de apiñamiento dentario anterior y restos radiculares en 2 casos $(0,05 \%)$. En la comunidad Toba fueron: caries dental en 29 casos $(0,97 \%)$, seguido de agenesia del incisivo lateral superior con I caso $(0,03 \%)$ y apiñamiento dentario con I caso (0,03\%) Tabla 2.

En la comunidad Mocoví la patología más frecuente es la gingivitis marginal crónica a partir de los 6 años con 5 casos (0,83\%), seguido de pólipo pulpar con I caso $(0,17 \%)$. A partir de los 14 años la patología más frecuente fue la gingivitis marginal crónica en 4 casos $(0,67 \%)$ seguido de periodontitis y macroglosia que se distribuyen proporcionalmente con I caso (0, I7\%). Tabla 3.

Con respecto a las patologías de tejidos duros, se observó a partir de los 6 años la caries dental con 23 casos $(0,85 \%)$, seguido de apiñamiento dentario severo en 2 casos $(0,07 \%)$ Tabla 4.

En la comunidad Toba las patologías herpes simple, pólipo pulpar y queilitis descamativa se distribuyen proporcionalmente con I caso $(0,33 \%)$. En el recambio dentario se observó la gingivitis marginal crónica con mayor frecuencia en 3 casos ( $1,00 \%)$. Tabla 5.

En cuanto a las patologías dentarias en los Mocovíes la más frecuente a partir de los 6 años fue la caries dental con 20 casos $(0,95 \%)$ disminuyendo a partir de los 14 años. Tabla 6.

Teniendo en cuenta el sexo, el predominio de patologías se presentó en el femenino siendo la gingivitis marginal crónica fue la más frecuente 


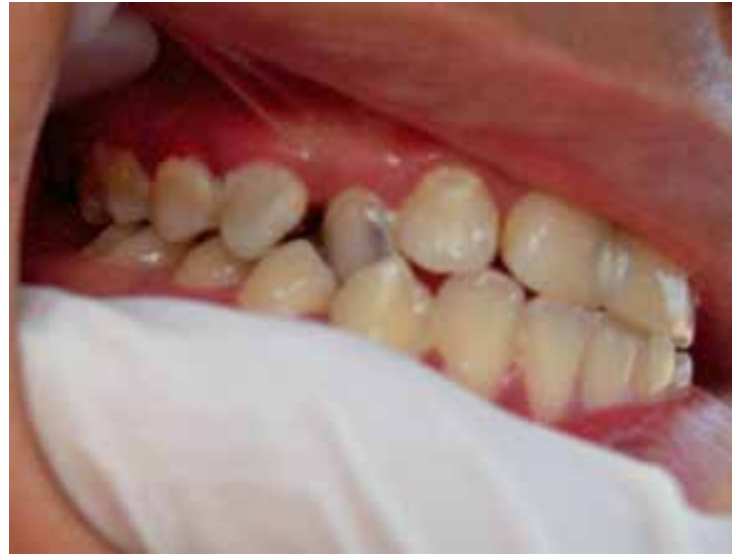

Figura I. Gingivitis marginal crónica. Caries. Comunidad Toba.

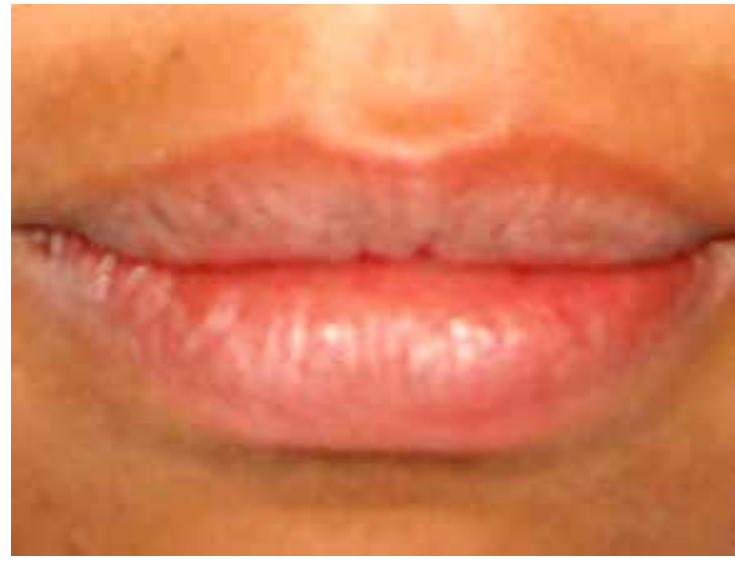

Figura 3. Queilitis descamativa crónica. Comunidad Mocoví.

con 6 casos $(0,75 \%)$ siguiéndole la caries dental con 30 casos (0,88\%) Tabla 7 y 8.

En la comunidad Toba, el sexo femenino fue el predominante asiento de las patologías como gingivitis marginal crónica 6 casos $(0,67 \%)$, pólipo pulpar $y$ herpes simple recidivante I caso $(0,17 \%)$ y la caries dental con 23 casos $(0,96 \%)$ y agenesia del incisivo lateral superior en I caso (0,04\%). Tabla 9 y 10.

Comparativamente, en ambas comunidades la patología de tejidos blandos más frecuentemente observada fue la gingivitis marginal crónica.

Los resultados no demostraron diferencias significativas en cuanto a las patologías de tejidos duros, siendo la caries dental la patología más frecuente. En menor medida se observaron casos de agenesia del incisivo lateral superior y apiñamiento dentario severo con alteraciones en la oclusión.

Históricamente en los grupos aborígenes se

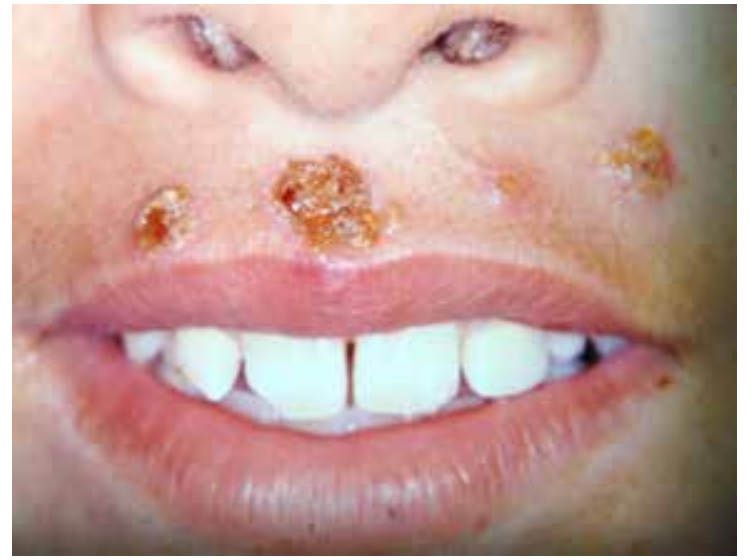

Figura 2. Herpes Simple Recidivante. Comunidad Toba.

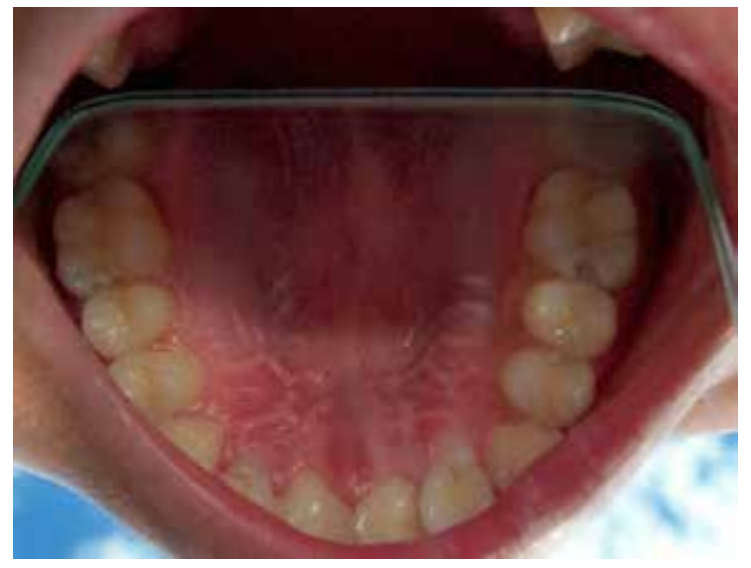

Figura 4. Caries oclusales interproximales. Ligero apiñamimento anterosuperior. Comunidad Toba.

han descripto menos patologías de tejidos duros y blandos que asienten en la cavidad bucal que los no aborígenes. Actualmente, ésta referencia parece haber cambiado.

Sehamsehula, RG refiere que las patologías observadas con mayor frecuencia son: caries dental, gingivitis marginal crónica, enfermedad periodontal, mala oclusión y apiñamiento dentario, resultados similares fueron obtenidos en este trabajo.

Jamieson, LM describió la presencia de caries particularmente alta en los niños, y la enfermedad periodontal más frecuente en adultos, resultados afines respecto de la caries dental fueron obtenidos, encontrándose escasamente enfermedad periodontal en la población infantil y adolescente en ambas comunidades.

Coincidiendo con Parker EJ, cuyos resultados fueron: el doble de casos de gingivitis, además se observaron anomalías oclusales como malo- 
Tabla I. Patologías de tejidos blandos diagnosticadas en las comunidades Mocoví y Toba.

\begin{tabular}{l|c|c|c|c}
\hline \multicolumn{1}{c|}{ Pomunidad } & \multicolumn{2}{c}{ Mocoví } & \multicolumn{2}{c}{ Toba } \\
\hline & FA & FR & FA & FR \\
\hline Gingivitis marginal crónica & 9 & 0,69 & 6 & 0,67 \\
\hline Herpes simple recidivante & -- & -- & 1 & $0,1 \mathrm{I}$ \\
\hline Macroglosia & $\mathrm{I}$ & 0,08 & -- & -- \\
\hline Periodontitis & $\mathrm{I}$ & 0,08 & -- & -- \\
\hline Pólipo pulpar & 2 & 0,15 & $\mathrm{I}$ & $0,1 \mathrm{I}$ \\
\hline Queilitis descamativa crónica & -- & -- & $\mathrm{I}$ & $0,1 \mathrm{I}$ \\
\hline Total & $\mathrm{I}$ & $\mathrm{I}, 00$ & 9 & $\mathrm{I}, 00$ \\
\hline
\end{tabular}

\begin{tabular}{crrc}
\multicolumn{1}{c}{ Estadístico } & Valor & $\mathrm{gl}$ & $\mathrm{p}$ \\
\hline Chi Cuadrado Pearson & 4,35 & 5 & 0,5002
\end{tabular}

Tabla 2. Patologías de tejidos duros diagnosticadas en las comunidades Mocoví y Toba.

\begin{tabular}{l|c|c|c|c}
\hline \multicolumn{1}{c|}{ Patologías } & \multicolumn{2}{c}{ Mocoví } & \multicolumn{2}{c}{ Toba } \\
\hline & FA & FR & FA & FR \\
\hline Agenesia de incisivo lateral superior & I & 0,02 & -- & -- \\
\hline $\begin{array}{l}\text { Agenesia de incisivo lateral sup y apiñamiento } \\
\text { dentario anterior }\end{array}$ & I & 0,02 & -- & -- \\
\hline Agenesia de incisivo lateral sup y caries & -- & -- & I & 0,03 \\
\hline Apiñamiento dentario anterior & I & 0,02 & -- & -- \\
\hline Apiñamiento dentario y caries & 2 & 0,05 & -- & -- \\
\hline Caries & 35 & 0,80 & 29 & 0,97 \\
\hline Pérdida de piezas dentarias & I & 0,02 & -- & -- \\
\hline Restos radiculares & I & 0,02 & -- & -- \\
\hline Restos radiculares, apiñamiento y caries & 2 & 0,05 & -- & -- \\
\hline Total & 44 & 1,00 & 30 & I,00 \\
\hline
\end{tabular}

\begin{tabular}{lccc} 
Estadístico & Valor & gl & $p$ \\
\hline Chi Cuadrado Pearson & 8,21 & 8 & 0,4135
\end{tabular}

Tabla 3. Patologías de tejidos blandos según edad en la comunidad Mocoví.

\begin{tabular}{|c|c|c|c|c|c|c|}
\hline \multirow{2}{*}{$\begin{array}{l}\text { Grupo Etáreo } \\
\text { Patologías }\end{array}$} & \multicolumn{2}{|c|}{$3-5$} & \multicolumn{2}{|c|}{$6-13$} & \multicolumn{2}{|c|}{ 14-20 } \\
\hline & FA & $\mathbf{F R}$ & FA & $\mathbf{F R}$ & FA & $\mathbf{F R}$ \\
\hline Gingivitis Marginal Crónica & -- & -- & 5 & 0,83 & 4 & 0,67 \\
\hline Macroglosia & -- & -- & -- & -- & $\mathrm{I}$ & 0,17 \\
\hline Periodontitis & -- & -- & -- & -- & $\mathrm{I}$ & 0,17 \\
\hline Pólipo Pulpar & $\mathrm{I}$ & 1,00 & 1 & 0,17 & -- & -- \\
\hline Total & $\mathrm{I}$ & $\mathrm{I}, 00$ & 6 & $\mathrm{I}, 00$ & 6 & $\mathrm{I}, 00$ \\
\hline
\end{tabular}

\begin{tabular}{cccc} 
Estadístico & Valor & gl & $p$ \\
\hline Chi Cuadrado Pearson & 8,79 & 6 & 0,1859
\end{tabular} 
Tabla 4. Patologías de Tejidos Duros según edad en la Comunidad Mocoví.

\begin{tabular}{|c|c|c|c|c|c|c|}
\hline \multirow{2}{*}{ Grupo Etáreo Patologías } & \multicolumn{2}{|c|}{$3-5$} & \multicolumn{2}{|c|}{$6-13$} & \multicolumn{2}{|c|}{ 14-20 } \\
\hline & FA & $\mathbf{F R}$ & FA & $\mathbf{F R}$ & FA & $\mathbf{F R}$ \\
\hline Agenesia de ILS & -- & --- & 1 & 0,04 & -- & --- \\
\hline Agenesia de ILS y Apiñamiento ant. & -- & --- & $\mathrm{I}$ & 0,04 & -- & --- \\
\hline Apiñamiento ant. & -- & --- & -- & --- & $\mathrm{I}$ & 0,13 \\
\hline Apiñam. Ant. y Caries dental & -- & --- & 2 & 0,07 & -- & --- \\
\hline Caries dental & 8 & 0,89 & 23 & 0,85 & 4 & 0,50 \\
\hline Pérdidas dentarias & -- & --- & -- & --- & $\mathrm{I}$ & 0,13 \\
\hline Restos radiculares & $\mathrm{I}$ & 0,11 & -- & --- & -- & --- \\
\hline Restos, caries y apiñamiento & -- & --- & -- & --- & 2 & 0,25 \\
\hline Total & 9 & 1,00 & 27 & 1,00 & 8 & 1,00 \\
\hline
\end{tabular}

\begin{tabular}{cccc} 
Estadístico & Valor & $g \mid$ & $p$ \\
\hline Chi Cuadrado Pearson & 25,49 & 14 & 0,0300
\end{tabular}

Tabla 5. Patologías de Tejidos Blandos según edad en la Comunidad Toba.

\begin{tabular}{l|c|c|c|c|c|c}
\hline Grupo Etáreo & \multicolumn{2}{c|}{ 3 - 5 } & \multicolumn{2}{c|}{ 6 - I 3 } & \multicolumn{2}{c}{ I4 - 20 } \\
\multicolumn{1}{c|}{ Patologías } & FA & FR & FA & FR & FA & FR \\
\hline Gingivitis Marginal Crónica & -- & -- & 3 & I,00 & 3 & I,00 \\
\hline Herpes Simple & $\mathrm{I}$ & 0,33 & -- & --- & -- & --- \\
\hline Pólipo pulpar & $\mathrm{I}$ & 0,33 & -- & --- & -- & --- \\
\hline Queilitis Descamat. & $\mathrm{I}$ & 0,33 & -- & --- & -- & --- \\
\hline Total & 3 & $\mathrm{I}, 00$ & 3 & $\mathrm{I}, 00$ & 3 & I,00 \\
\hline
\end{tabular}

Estadístico $\quad$ Valor $\mathrm{gl} \quad \mathrm{P}$

Chi Cuadrado Pearson $9,00 \quad 6 \quad 0,1736$

Tabla 6. Patologías de Tejidos Duros según edad en la Comunidad Toba.

\begin{tabular}{ll|c|c|c|c|c|c}
\hline Grupo Etáreo & \multicolumn{2}{c|}{ 3-5 } & \multicolumn{2}{c|}{ 6-13 } & \multicolumn{2}{c}{ 14-20 } \\
\hline Agenesia de ILS y caries & FA & FR & FA & FA & \multicolumn{2}{c}{ FR } \\
\hline Caries dental & -- & --- & I & 0,05 & -- & -- \\
\hline Total & 2 & 1,00 & 20 & 0,95 & 7 & 1,00 \\
\hline
\end{tabular}

\begin{tabular}{lccc} 
Estadístico & Valor & $g \mid$ & $p$ \\
\hline Chi Cuadrado Pearson & 0,44 & 2 & 0,8012
\end{tabular}

Tabla 7. Patologías de tejidos blandos según sexo en la comunidad Mocoví.

\begin{tabular}{|c|c|c|c|c|}
\hline \multirow{3}{*}{$\begin{array}{ll}\text { Grupo Sexo } & \\
\text { Gingivitis Marginal Crónica } & \\
\end{array}$} & \multicolumn{2}{|c|}{ Femenino } & \multicolumn{2}{|c|}{ Masculino } \\
\hline & \multicolumn{2}{|c|}{ FA $\quad F R$} & \multicolumn{2}{|c|}{ FA $\quad F R$} \\
\hline & 6 & 0,75 & 3 & 0,60 \\
\hline Macroglosia & 1 & 0,13 & -- & --- \\
\hline Periodontitis & -- & --- & $\mathrm{I}$ & 0,20 \\
\hline Pólipo pulpar & 1 & 0,13 & $\mathrm{I}$ & 0,20 \\
\hline Total: & 8 & 1,00 & 5 & 1,00 \\
\hline
\end{tabular}

\begin{tabular}{cccc} 
Estadístico & Valor & $g \mid$ & $p$ \\
\hline Chi Cuadrado Pearson & 2,44 & 3 & 0,48
\end{tabular} 
Tabla 8. Patologías de tejidos duros según sexo en la comunidad Mocoví.

\begin{tabular}{l|c|c|c|c}
\hline \multirow{2}{*}{$\begin{array}{l}\text { Grupo } \\
\text { Sexo }\end{array}$} & \multicolumn{2}{c|}{ Femenino } & \multicolumn{2}{c}{ Masculino } \\
\hline Agenesia ILS & \multicolumn{2}{c}{ FA } & FR & \multicolumn{2}{c}{ FA } & FR \\
\hline Agenesia ILS y Apiñamiento dent. & I & 0,03 & -- & --- \\
\hline Agenesia ILS y caries & -- & --- & I & 0,10 \\
\hline Apiñamiento ant. & -- & --- & I & 0,10 \\
\hline Caries dental & 2 & 0,06 & -- & --- \\
\hline Pérdidas dentarias & 30 & 0,88 & 5 & 0,50 \\
\hline Restos radiculares & I & 0,03 & -- & --- \\
\hline Restos, apiñam. y caries & -- & --- & I & 0,10 \\
\hline Total: & -- & --- & 2 & 0,20 \\
\hline
\end{tabular}

Estadístico Valor $g$ l $p$

$\begin{array}{llll}\text { Chi Cuadrado Pearson } & 19,60 & 7 & 0,0065\end{array}$

Tabla 9. Patologías de tejidos blandos según sexo en la comunidad Toba.

\begin{tabular}{l|c|c|c|c}
\hline \multirow{2}{*}{$\begin{array}{l}\text { Grupo Patologías } \\
\text { Sexo }\end{array}$} & \multicolumn{2}{c|}{ Femenino } & \multicolumn{2}{c}{ Masculino } \\
\hline Gingivitis Marginal Crónica & 4 & 0,67 & 2 & 0,67 \\
\hline Herpes Simple & $\mathrm{I}$ & 0,17 & -- & --- \\
\hline Pólipo pulpar & $\mathrm{I}$ & 0,17 & -- & --- \\
\hline Queilitis Descam. & -- & --- & $\mathrm{I}$ & 0,33 \\
\hline Total: & 6 & $\mathrm{I}, 00$ & 3 & $\mathrm{I}, 00$ \\
\hline
\end{tabular}

Estadístico Valor $g$

Chi Cuadrado Pearson $3,00 \quad 3 \quad 0,3916$

Tabla 10. Patologías de tejidos duros según sexo en la comunidad Toba.

\begin{tabular}{l|c|c|c|c}
\hline \multirow{2}{*}{$\begin{array}{l}\text { Grupo } \\
\text { Sexo }\end{array}$} & \multicolumn{2}{c|}{ Femenino } & \multicolumn{2}{c}{ Masculino } \\
\hline Agenesia ILS y caries dental & \multicolumn{2}{c}{ FA } & FR & \multicolumn{2}{c}{ FA } & FR \\
\hline Caries dental & I & 0,04 & -- & -- \\
\hline Total: & 23 & 0,96 & 6 & 1,00 \\
\hline
\end{tabular}

\begin{tabular}{ccccc} 
Estadístico & Valor & $g \mid$ & $\mathrm{p}$ \\
\hline Chi Cuadrado Pearson & 0,26 & $\mathrm{I}$ & $0,6 \mathrm{III}$ &
\end{tabular}


REVISTA FACULTAD DE ODONTOLOGÍA

ISSN No 1668-7280 - Vol. VI № 2 - 2013

43
INVESTIGACIÓN

Determinación de las patologías bucales

de la población infantil y adolescente

en dos pueblos originarios del NEA

argentino. clusión severa, apiñamiento dentario anterior en un 5,5\% y enfermedad periodontal en los niños aborígenes australianos.

Jamieson LM y Armfield JM describieron que la mayor presencia de caries fue observada en los aborígenes cuyas edades oscilaban entre los 18 y 20 años, sin embargo el grupo etáreo afectado con más actividad de caries fue el de la etapa de recambio dentario, es decir entre los 6 y 13 años. Se coincide con Roberts-Thomson KF quien concluyó que los niños indígenas son más propensos a tener caries dental en todas las edades afectando la dentición temporaria y permanente; y que a la edad de 6 años, el 72\% de los niños indígenas tenían alguna caries dental en comparación con el $38 \%$ de niños no indígenas.

Con respecto el sexo más afectado Parker EJ, demostró que la población más propensa a padecer caries dental y socialmente desfavorecida fueron los niños en edad pre escolar, del sexo femenino, coincidiendo con este autor el sexo más afectado fue el femenino en el grupo etáreo de 6 a 13 años en ambas comunidades.

Según Linares Lizarazo, LR los índices de caries más altos en la población aborigen Sikuani fueron obtenidos en edades entre 15 y 17 años, a diferencia de los resultados obtenidos donde la población más afectada por la caries fue la comprendida entre 6 y 12 años, en ambas comunidades. Sin embargo se coincide respecto al hecho de pertenecer a sectores menos favorecidos en cuanto al acceso a la atención odontológica debido a la distancia que deben recorrer estas etnias; asimismo con Roberts-Thomson quienes atribuyeron que el estado de salud observado se relaciona con la situación geográfica y económica de las mismas.

\section{Conclusión}

En la comunidad Mocoví las patologías de tejidos blandos más frecuentemente diagnosticadas fueron gingivitis marginal crónica y pólipo pulpar y las que afectaron los tejidos duros fueron: caries dental y apiñamiento dentario.

En la comunidad Toba las patologías de tejidos blandos más frecuentemente detectadas fueron: gingivitis marginal crónica, herpes simple y queilitis crónica descamativa y las de tejidos duros fueron: caries dental, agenesia de incisivo lateral superior y apiñamiento dentario.

Comparando ambas comunidades las patologías más frecuentes fueron: en tejidos blandos predominaron la gingivitis marginal crónica y en los tejidos duros las alteraciones más frecuentes fueron la caries dental.

Destacándose que en ambas comunidades las alteraciones detectadas tienen relación con factores como la escasa higiene y fundamentalmente la dificultad en el acceso a centros de salud para su atención, debido a las distancias que deben recorrer para tal fin.

En ambas comunidades según la edad, el grupo etáreo más afectado fue el de 6 a 13 años, y el sexo más afectado fue el femenino.

Teniendo en cuenta los derechos a la salud de estos pueblos, es necesario incrementar los programas de salud odontológica que garanticen el cumplimiento de atención, diagnóstico y tratamiento de las alteraciones que se manifiesten en la cavidad bucal y zonas peribucales, siempre dentro del marco de respeto y tolerancia por la diversidad étnica, la interculturalidad, costumbres e idiosincrasia de estos pueblos originarios. 
REVISTA FACULTAD DE ODONTOLOGÍA

ISSN No 1668-7280 - Vol. VI № 2 - 2013

44
INVESTIGACIÓN

De Langhe - González

\section{Bibliografía}

I. Burbano Delgado, M. E. El impacto de la colonización española: Evidencias Paleopatológicas e isotópicas de cambios en la salud oral y reducción de la diversidad en la dieta en sociedades colombianas nativas del sur Occidental de Colombia. Rev. De Estomatología. 2007; 15 (2 supl I): 17-37.

2. Azcona MS. Procesos transaccionales y desarrollo autogestivo en salud y atención bucal entre los grupos (Qom) tobas asentados en Los Pumitas (Rosario), Argentina. Pap. trab. - Cent. Estud. Interdiscip. Etnolingüíst. Antropol. Sociocult. 2010; (20): II-2I.

3. Hernández Restrepo Fj; Riaño Barreto C; Galvis de Hernández MC. Salud oral en las comunidades visitadas por la gran expedición humana. Geografia Humana de Colombia Variación Biológica y Cultural en Colombia. Tomo I [revista en internet] 2012:[ acceso 16 mayo 20I2] Disponible en: http://www.banrepcultural.org/blaavirtual/ geografia/geofrafl/salud.htm

4. Linares Lizarazo LR, Ruiz Paredes NR, Herrera D, Gomez RA. Caries dental y condiciones de higiene oral en niños indígenas Sikuani, municipio de Puerto Gaitán. Colombian Journal of Dental Research. 20I0; I (2)

5. Jamieson LM, Sayers SM. Oral health investigations of indigenous participants in remote settings: a methods paper describing the dental component of wave III of an Australian Aboriginal birth cohort study. BMC Oral Health. 2008; 8: (24)

6. Lawrence HP, Binguis D, Douglas J, McKeown L, Switzer B, Figueiredo R, Reade M. Oral health inequalities between young Aboriginal and non-Aboriginal children living in Ontario, Canada. Community Dent Oral Epidemiol. 2009; 37(6): 495-508.

7. Sehamsehula RG, Cooper MH, Adkins BL, Barmes DE, Agus HM. Oral conditions in Australian children of Aboriginal and Caucasian descent. Community Dent. Oral Epidemiol. 1980; 8: 365-369

8. Davies A.J, Spencer A, Westwater AJ, Simmons B. Dental caries among Australian Aboriginal, non- Aboriginal Australian-born, and overseas-born children Bulletin of the World Health Organization. 1997; 75 (3): 197-203
9. Jamieson LM, Armfield JM, Roberts-Thomson KF, Sayers SM. A retrospective longitudinal study of caries development in an Australian Aboriginal birth cohort. Caries Res. 20I0; 44(4):4I5-20.

10. Kruger E, Perera I, Tennant M. Primary oral health service provision in Aboriginal Medical Services-based dental clinics in Western Australia. Aust J Prim Health. 2010; I6(4):291-5.

II. Roberts-Thomson Kaye F, Spencer A, Jamieson Lisa M. Oral health of Aboriginal and Torres Strait Islander Australians. MJA. 2008; 188 (10): 592-593.

12. Parker EJ, Jamieson LM. Oral health comparisons between children attending an Aboriginal health service and a Government school dental service in a regional location. Rural Remote Health. [revista en internet] 2007; 7 (2): 625.

13. Kaye Roberts-Thomson. Oral health of Aboriginal Australians: Australian Research Centre for Population Oral Health, The University of Adelaide, South Australia. Australian Dental Journal. 2004; 49: I5I-I53.

14. Filho P, Santos RV, Vettore MV. Saúde bucal dos índios Guaraní no Estado do Rio de Janeiro, Brasil. Cad. Saúde Pública [revista en internet]. 2009; [citado el 08 de Abril de 2013] 25(I): 37-46. Disponible en: http://www. scielo.br/scielo.php?script=sci_arttext\&pid=SOI0231 IX2009000 I 00004\&lng=pt. http://dx.doi. org/I0.1590/S0102-31IX2009000100004.

15. Cuyul A, Rovetto M, Specogna M. Pueblos Indígenas y sistemas de información en salud: La variable étnica en seis provincias Argentina. Rev Argen Salud Pública. 201 I; 2 (7) 12 - 18.

16. Beltrán Aguilar E, Bordoni N. Guía básica para el diseño de estudios epidemiológicos destinados a la toma de decisiones sanitarias en el campo de la salud bucal. Revista de la Facultad de Odontología (UBA). 201 I; 26 (60) 39-47

17. Grispan, D. Enfermedades de la Boca. Semiología, Patología, Clínica y Terapéutica de la Mucosa Bucal. Buenos Aires. Argentina: Mundi S.A.C.I.F; 198---

18. Nicolosi LN. Evaluación del paciente. En: Polotto F, editor. Semiología en la práctica de la odontológica. Chile: Mc Graw- Hill Interamericana; 2000. p I-I8. 